\title{
Análise da concepção política do Currículo São Paulo Faz Escola
}

\section{Analysis of political conception of the Curriculum São Paulo Faz Escola}

\section{Análisis de la concepción política del Currículo São Paulo Faz Escola}

José Antônio Leandro Filho ${ }^{1}$

Marcos Vinicius Francisco ${ }^{2}$

Erika Porceli Alaniz ${ }^{3}$

DOI: http://dx.doi.org/10.20435/serie-estudos.v0i0.1228

\begin{abstract}
Resumo: Assume-se a premissa de que todo currículo escolar esboça a ideologia de um governo e de seus agentes. Nesta investigação, analisou-se a concepção política presente no currículo do Estado de São Paulo, intitulado São Paulo Faz Escola. Esta é uma pesquisa crítico-interpretativa e adotou-se como procedimento metodológico a análise documental. Assumiu-se como referencial teórico e epistemológico o Método do Materialismo Histórico Dialético. Os resultados apontam que a política educacional praticada no referido estado confere ênfase ao discurso de competências e habilidades, em consonância com os cânones do neoliberalismo. Tais preceitos advêm das influências dos órgãos regulatórios internacionais que se encontram a serviço do capital e que privilegiam a educação voltada para a adaptação ao mercado de trabalho e a manutenção das relações sociais. Constatou-se, ainda, que o currículo é pragmático, sendo oferecida uma versão pronta e acabada para professores e estudantes, aspectos esses que esvaziam o sentido e significado da práxis-pedagógica, numa perspectiva transformadora.
\end{abstract}

Palavras-chave: currículo; política educacional; São Paulo Faz Escola.

Abstract: It is assumed the premise that every school curriculum outlines the ideology of a government and its agents. This research analyzed the political conception present in the curriculum of the São Paulo State, entitled São Paulo Faz Escola. This is a critical-interpretive research and a document analysis was adopted as a methodological procedure. The Historical Dialectical

\footnotetext{
${ }^{1}$ Secretaria Estadual de Educação de São Paulo, São Paulo, Brasil.

2 Universidade Estadual de Maringá (UEM), Maringá, Paraná, Brasil.

${ }^{3}$ Universidade Estadual de Mato Grosso do Sul (UEMS), Campo Grande, Mato Grosso do Sul, Brasil.
} 
Materialism Method was assumed as theoretical and epistemological reference. The results show that educational policies practiced in the São Paulo state gives emphasis to speech skills and abilities, in line with the canons of neo-liberalism. Such precepts derive from the influences of international regulatory agencies that are at the service of capital and which emphasize education aimed to adapt in the job market and the maintenance of social relations. It was found also that the curriculum is pragmatic, being offered a version ready and finished for teachers and students, aspects that empty the meaning and significance of practice-teaching in changing perspective.

Keywords: curriculum; educational policy; São Paulo Faz Escola.

Resumen: Se asume la premisa de que todo currículo escolar esboza la ideología de un gobierno y de sus agentes. En esta investigación se analizó la concepción política presente en el currículo del Estado de São Paulo, titulado São Paulo Faz Escola. Esta es una investigación crítico-interpretativa y se adoptó como procedimiento metodológico el análisis documental. Se asume como referencial teórico y epistemológico el Método del Materialismo Histórico Dialéctico. Los resultados apuntan que la política educativa practicada en dicho estado confiere énfasis al discurso de competencias y habilidades, en consonancia con los cánones del neoliberalismo. Tales preceptos provienen de las influencias de los órganos regulatorios internacionales que se encuentran al servicio del capital y que privilegian la educación orientada a la adaptación al mercado de trabajo y el mantenimiento de las relaciones sociales. Se constató, además, que el currículo es pragmático, siendo ofrecida una versión lista y acabada para profesores y estudiantes, aspectos que vacían el sentido y significado de la praxis pedagógica, en una perspectiva transformadora.

Palabras clave: currículo; política educativa; São Paulo Faz Escola.

\section{INTRODUÇÃO}

No que tange às discussões sobre currículo ${ }^{4}$, nas últimas décadas, os países emergentes, entre eles o Brasil, ao firmarem acordos e empréstimos junto às agências regulatórias a serviço do capital, tais como Banco Mundial (BM), Fundo Monetário Internacional (FMI), Organização para a Cooperação e Desenvolvimento Econômico (OCDE) e Organização Mundial de Comércio (OMC), assumiram as exigências de implementar políticas públicas de cunho neoliberal. No campo educacional, o discurso governamental vem enfatizando que a educação deve se alinhar às necessidades do mercado e conferir ênfase ao preparo dos estudantes para o trabalho (HADDAD, 2008; CHIZZOTTI; PONCE, 2012; PEREIRA, 2018; PEREIRA; SILVA, 2018).

\footnotetext{
${ }^{4}$ Vários estudiosos se propuseram a buscar uma definição de currículo dentro de diferentes momentos da história, sendo que mais de trinta definições foram encontradas. "Currículo" comumente é utilizado para designar o programa a ser percorrido por uma disciplina ou um curso, a fim de se esclarecerem as práticas educativas a serem desenvolvidas (MALTA, 2013).
} 
Neste artigo, optou-se por abordar alguns aspectos sobre o currículo, a partir da década de 1970, ao entender que tal contexto foi decisivo no cenário internacional e nacional, sobretudo na produção das políticas educacionais alinhadas a um modelo gerencial de educação e de caráter economicista (HADDAD, 2008; PEREIRA; SILVA, 2018). Esse movimento influenciou, inclusive, a elaboração do Programa São Paulo Faz Escola, foco de análise.

Na década de 1970, ganhou ênfase o tecnicismo, entendido como o processo de reorganização dos sistemas educativos, numa dimensão objetiva e operacional. Freitas (2012) salienta que a pedagogia tecnicista define o que os professores e estudantes estudarão e como estudar. O autor pondera que, da mesma forma como os empresários se utilizam da tecnologia na produção empresarial, busca-se sua aplicação na educação.

Freitas (2012) avalia, ainda, que na atualidade o tecnicismo ganhou nova roupagem e objetivos, podendo ser chamado de neotecnicismo. As características deste novo processo são marcadas por uma "teoria da responsabilização, meritocracia e gerencialista, onde se propõe a mesma racionalidade técnica de antes na forma de 'standards', ou expectativas de aprendizagens medidas em testes padronizados" (FREITAS, 2012, p. 383).

Por conseguinte, as políticas educacionais, nessa perspectiva, adotam a homogeneização de currículos e materiais oferecidos aos estudantes e professores com o pretenso objetivo de igualar as oportunidades. Assume-se que as diferenças que aparecem nesse processo, fruto da desigualdade socioeconômica, são obliteradas mediante o discurso de responsabilização de professores e estudantes pelos êxitos não alcançados/obtidos, em especial, nas avaliações nacionais de larga escala.

$E$, por mais que o discurso oficial apregoe que os currículos sejam produzidos coletivamente, assiste-se a um processo diametralmente oposto. Em muitos casos, os professores têm a sua autonomia cerceada e especialistas são contratados pelos sistemas estaduais e municipais, a fim de esquadrinhar as bases dos referidos currículos, em consonância com a manutenção da hegemonia política e alinhados a uma concepção mercantil de educação (CATANZARO, 2012; FERNANDES, 2014).

Entre os métodos mercantis, a adoção de currículos privados pelos sistemas públicos de ensino converte-se em um dos grandes modelos rentáveis aos gran- 
des conglomerados da área de educação. Acumulam cada vez mais mercados e expandem seus negócios por meio das parcerias público-privadas.

Nessa perspectiva, Adrião, Damaso e Galzerano (2013), ao analisarem os municípios paulistas, com até 50 mil habitantes, que adotaram Sistemas Privados de Ensino pelas redes municipais, identificaram quatro aspectos que favoreceram esse processo:

i) Após o processo de descentralização da educação brasileira, via municipalização de sua oferta, durante a década de 1990 e diante das propostas de reformas da gestão pública (restrição de gastos, terceirização de serviços e o aumento da responsabilização - accountability), as empresas educacionais perceberam um grande filão nos municípios pequenos e pouco aparelhados (ADRIÃO; DAMASO; GALZERANO, 2013);

ii) As "alterações na gestão pública, orientadas por uma perspectiva gerencialista, materializada na Emenda Constitucional n. 19/1998" corroboraram “na propositura, a partir de 2001, da Lei Complementar n. 101/2000 (Lei de Responsabilidade Fiscal)", que impactou negativamente na educação pública, sobretudo por meio do "controle dos gastos públicos por meio da restrição de gastos com pessoal" (ADRIÃO; DAMASO; GALZERANO, 2013, p. 437);

iii) Na busca pela ampliação de mercados, as empresas privadas que vendem produtos e serviços educacionais apresentam tendências de oligopolização, ao passo que "aceleram as fusões de empresas e a aquisição de marcas e grupos brasileiros por corporações multinacionais" (ADRIÃO; DAMASO; GALZERANO, 2013, p. 438);

iv) Na atualidade, a maioria dos gestores públicos e professores inicia a atuação profissional nessa lógica privatizante e defende a continuidade do uso dos materiais apostilados, embora isso os impeça de planejarem e organizarem a rotina de seu trabalho. Há, assim, uma adesão aos discursos neotecnicistas, ou seja, a defesa de que a organização do trabalho terá maior eficiência, além de sanar as deficiências do professor e maximizar os efeitos de sua intervenção.

Diante desses aspectos, neste artigo, assumiu-se a proposição de analisar a concepção política do Currículo do Estado de São Paulo, denominado São Paulo Faz Escola. 


\section{MÉTODO}

Esta é uma pesquisa crítico-interpretativa e adotou-se como procedimento metodológico a análise documental. Analisou-se qualitativamente o Currículo São Paulo Faz Escola (SÃO PAULO, 2007a, 2007b, 2008, 2009, 2010, 2014a, 2014b). Com relação à técnica de análise documental, Ludke e André (1986) e Severino (2012) apontam que as informações já analisadas por outras pessoas podem ser reavaliadas por novas técnicas e novas problemáticas para ganharem qualidade na investigação. De acordo com os autores, são considerados documentos todos os materiais escritos e que venham a ser usados como fonte de informações.

Nesse sentido, após a análise do São Paulo Faz Escola, elegeram-se dois eixos analíticos: 1 - Produção do Programa São Paulo Faz Escola e sua concepção ideológica; 2 - O currículo oficial a partir do discurso de competências de habilidades. Ludke e André (1986) afirmam que as categorias analíticas (eixos analíticos) devem ser vistas como fundamentais, pois por meio delas é que o pesquisador norteará as análises dos resultados obtidos no processo de investigação.

No primeiro eixo analítico, identificaram-se alguns aspectos presentes na gênese da produção e implantação do São Paulo Faz Escola, a concepção política do Programa São Paulo Faz Escola, bem como o tipo de política educacional que sustentou a elaboração do referido. No segundo eixo analítico, procedeu-se à análise do discurso de competências e habilidades exigidas, além de enfatizar o papel que estas têm no atual sistema de organização das relações sociais.

\section{ANÁLISE DO PROGRAMA SÃO PAULO FAZ ESCOLA}

Neste tópico, procedeu-se pela análise do discurso oficial do Programa São Paulo Faz Escola, elegendo-se os seguintes eixos: 1 - Produção do Programa São Paulo Faz Escola e sua concepção ideológica; 2 - O currículo oficial a partir do discurso de competências de habilidades.

\subsection{Produção do Programa São Paulo Faz Escola e sua concepção ideológica}

O Programa São Paulo Faz Escola foi criado em 2008, no mandato do então governador José Serra (PSDB), e implementado por meio da Secretaria de Estado da Educação de São Paulo (SEE-SP), na gestão de Maria Helena Guimarães de Castro. "O referido programa integra uma reforma curricular que teve origem 
em meio à divulgação do plano de metas [...] de melhoria da educação pública do estado de São Paulo, estipulado a partir de 2007 pela SEE-SP" (PAES; RAMOS, 2014, p. 55).

Na publicação do Diário Oficial, de 21 de agosto de 2007, o título da matéria apresentada era o seguinte: "Secretaria da Educação de São Paulo cria nova agenda para a educação pública” (SÃO PAULO, 2007a, p. 1). Na ocasião, foram apresentadas dez metas que deveriam ser atingidas até 2010, a fim de se melhorarem os índices de aprendizagem constatados pelos censos escolares, além das taxas de reprovação, que evidenciavam o desempenho insuficiente do sistema estadual de ensino. Houve a menção, inclusive, de que se estabeleceria uma política de articulação entre o Estado e seus municípios, na expectativa de se compartilhar uma "mesma proposta curricular, com as indicações das expectativas de aprendizagem" (SÃO PAULO, 2007a, p. 1).

Tal cenário anunciava o currículo padronizado, a ser instituído, no ano seguinte, na rede estadual (ciclo II do Ensino Fundamental e Ensino Médio), confirmado por meio da Resolução n. 92, de 19 de dezembro de 2007, na qual se reforçava "a implementação, em 2008, das propostas curriculares de ensino fundamental e médio organizadas por esta Pasta" (SÃO PAULO, 2007b, p. 1). Dessa forma, na análise do processo de produção do São Paulo Faz Escola, é importante resgatar mais elementos do discurso governamental, a fim de explicitar a síntese de suas múltiplas determinações, na expectativa de ampliar a análise do objeto em tela, para além da aparência fenomênica.

A Secretaria da Educação do Estado de São Paulo propôs, em 2008, um currículo básico para as escolas da rede estadual nos níveis de Ensino Fundamental (Ciclo II) e Ensino Médio. Com isso, pretendeu apoiar o trabalho realizado nas escolas estaduais e contribuir para a melhoria da qualidade das aprendizagens dos alunos. Esse processo partiu dos conhecimentos e das experiências práticas já acumulados, ou seja, partiu da recuperação, da revisão e da sistematização de documentos, publicações e diagnósticos já existentes e do levantamento e análise dos resultados de projetos ou iniciativas realizados. No intuito de fomentar o desenvolvimento curricular, a Secretaria da Educação tomou assim duas iniciativas complementares. A primeira delas foi realizar amplo levantamento do acervo documental e técnico pedagógico existente. A segunda deu início a um processo de consulta a escolas e professores para identificar, sistematizar e divulgar boas práticas existentes nas escolas de São Paulo. (SÃO PAULO, 2010, p. 7) 
Embora o discurso governamental mencione que as escolas tenham sido consultadas, a fim de subsidiar a produção do currículo, esse parece não ter sido o movimento real. Catanzaro (2012, p. 19) denuncia que "[...] os cadernos produzidos para a proposta curricular foram elaborados por meio de convites realizados pela Fundação Vanzolini a profissionais ligados às universidades estaduais".

Para Chizzotti e Ponce (2012, p. 32), "as reformas curriculares, recobertas por discursos científicos, pressupostos epistemológicos e axiológicos, manifestam, nos consensos e contradições ideológicas, a luta pela hegemonia política". O discurso oficial propõe o currículo como um instrumento social de responsabilidade coletiva, porém o que se evidencia é um distanciamento entre o discurso e a prática.

Tais medidas políticas de centralização curricular são adotadas em nome de uma educação de qualidade, entretanto essa qualidade não considera a questão cultural de cada região ou das pessoas diretamente ligadas à educação. A implantação de um "novo" currículo hegemônico é reforçada pelos discursos de inovação e maximização da qualidade, em relação aos modelos curriculares anteriores.

Para satisfazer essa nova demanda de um currículo centralizado, estados e municípios com recursos suficientes criaram seus próprios currículos ao contratarem equipes de especialistas que se encarregaram de elaborá-lo. Tal exemplo se aplica ao Programa São Paulo Faz Escola. Outros estados e municípios sem recursos recorreram a programas já existentes utilizados por franquias particulares (CHIZZOTTI; PONCE, 2012; ADRIÃO; DAMASO; GALZERANO, 2013; FERNANDES, 2014; PEREIRA, 2018).

Constatou-se que profissionais da educação, da rede estadual, ficaram à margem do processo de elaboração do material. No início de 2008, mais especificamente em 18 de fevereiro, as mais de cinco mil escolas estaduais paulistas de Ensino Fundamental II e Ensino Médio iniciaram o ano letivo com um "Jornalzão", com textos das diferentes disciplinas que compunham o currículo, porém a ênfase recaiu nos conhecimentos matemáticos e de língua portuguesa. O material fazia parte do Projeto Reforço Estudantil a ser trabalhado até o fim do mês de março, na expectativa de que, na sequência, o currículo unificado - São Paulo Faz Escola - fosse efetivado (GIAVARA, 2012).

Todo esse processo foi alvo de críticas, diante da dicotomia presente. 0 material foi produzido por professores universitários, alheios à realidade da rede estadual de ensino, e sem participação da comunidade escolar (CATANZARO, 2012; 
LEANDRO FILHO, 2015). Haddad (2008), Catanzaro (2012) e Fernandes (2014) afirmam existir muitos fatores sociais que interferem na não efetivação e garantia de uma educação de qualidade, sendo um deles relacionado às escolhas políticas dos profissionais que confeccionam os currículos dos estados e municípios. Esses profissionais contratados, muitas vezes, nem sequer conhecem a realidade na qual o currículo será implantado, o que interfere diretamente na qualidade do processo de ensino e aprendizagem.

Ao analisar a implantação do Programa São Paulo Faz Escola, percebe-se que, intrinsecamente, ele abarca os ideários neoliberais desenvolvidos pelo Banco Mundial. Tais ideários são seguidos à risca por especialistas ligados à SEE (ROSSI, 2011).

É importante frisar que os ideários neoliberais ganharam força mundial, a partir da década de 1980, por meio das figuras de Ronald Reagan, nos Estados Unidos, e Margaret Thatcher, na Inglaterra, considerados peças-chave em reformas educacionais (ANDERSON, 1995; CHIZZOTTI; PONCE, 2012). A partir do ideário liberal, os dois países passaram a conceber a educação na lógica empresarial e de produtividade, ao criar, por exemplo, um ranqueamento das instituições educacionais. As problemáticas educacionais passaram a ser vistas como passíveis de serem solucionadas via tutela da iniciativa privada (FREITAS, 2012; PEREIRA, 2018). Outros países do globo seguiram esta lógica e centralizaram seus sistemas de ensino a partir de avaliações externas, na intenção de gerenciá-los, ou seja, tais sistemas de ensino adotaram as mesmas regras do mercado (PEREIRA, 2018).

Catanzaro (2012) e Chizzotti e Ponce (2012) reiteram que nos anos 1990, no século passado, a União Europeia convocou um grupo de especialistas para determinar quais competências eram chaves no desenvolvimento das pessoas e que seriam capazes de atender aos interesses do mercado internacional. Ou seja, esses especialistas determinaram o tipo de currículo que os estabelecimentos de ensino deveriam difundir. Adepto desta lógica, o Brasil assumiu com grande força, em especial, a partir da referida década, a tendência liberal na produção de seus currículos.

Haddad (2008) e Pereira e Silva (2018) destacam que, atrelada a este novo padrão da educação, está a condição sine qua non de apontar a influência que os órgãos regulatórios internacionais tiveram nesse processo (BM, FMI, OMC 
e OCDE). Por meio da ajuda financeira, empréstimos, tais organismos buscam controlar ações em vários setores, sobretudo nos países em desenvolvimento, como é o caso do Brasil. Impõe-se uma lógica de mercado em relação ao âmbito social, o que interfere na qualidade das reformas educacionais (HADDAD, 2008; LOPES; MATHEUS, 2014).

Os especialistas dessas organizações é que determinam o tipo de ações que cada nação tomará, a fim de atender à lógica do mercado em vigência. Em linhas gerais, os órgãos agem de forma a pressionar os países que necessitam de empréstimos a internacionalizar vários setores, inclusive o educacional. Um dos setores mais influenciados e abertos ao capital estrangeiro é o de prestação de serviços, o qual a educação faz parte (HADDAD, 2008; PEREIRA; SILVA, 2018).

Nessa lógica, sinalizam Meyer e Ramírez (2002), Chizzotti e Ponce (2012) e Pereira (2018), há uma preocupação muito grande com a padronização mundial dos currículos. As reformas educacionais e a universalização curricular proposta aos países europeus pela OCDE também foram exigidas ao Brasil pelo BM, como contrapartida para se obter apoios financeiros (PEREIRA, 2018).

Todos esses aspectos supracitados corroboram com as características do neotecnicismo (FREITAS, 2012). O gerenciamento praticado pelo Estado de São Paulo segue a mesma linha e responsabiliza a unidade escolar pelas notas obtidas pelos estudantes nas avaliações do Sistema de Avaliação de Rendimento Escolar do Estado de São Paulo (SARESP) ${ }^{5}$ (SÃO PAULO, 2008). Este fato também está em consonância com as três categorias apresentadas que definem a política neotecnicista, ou seja, os "testes para os estudantes, divulgação pública do desempenho da escola e recompensas e sanções" (FREITAS, 2012, p. 383). Na sequência, são apresentados trechos da Lei Complementar n. 1.078, de 17 de dezembro de 2008, que instituiu a bonificação por resultados:

Artigo 3o- A Bonificação por Resultados- BR será paga na proporção direta do cumprimento das metas definidas para a unidade de ensino ou administrativa onde o servidor estiver desempenhando suas funções, observados os artigos 8ㅇ, 9 e 10 desta lei complementar.

\footnotetext{
${ }^{5}$ No Saresp, estudantes dos 3ㅇ, 5으, 70 e 9o anos do Ensino Fundamental e da 3a série do Ensino Médio são avaliados por meio de provas com questões de Língua Portuguesa, Matemática, Ciências Humanas, Ciências da Natureza e redação. Os resultados, utilizados para orientar as ações da Pasta, também integram o cálculo do Índice de Desenvolvimento da Educação do Estado de São Paulo (Idesp).
} 
$\S 1$ 10- Para os fins do disposto no "caput" deste artigo, as unidades de ensino e administrativas serão submetidas à avaliação destinada a apurar os resultados obtidos em cada período, de acordo com os indicadores e metas referidos nos artigos 40 a 70 desta lei complementar.

$\S 2$-- As metas deverão evoluir positivamente em relação aos mesmos indicadores do período imediatamente anterior ao de sua definição, excluídas alterações de ordem conjuntural que independam da ação do Estado, na forma a ser disciplinada em resolução do Secretário da Educação. (SÃO PAULO, 2008, p. 1).

A avaliação mencionada na Lei Complementar refere-se ao SARESP. Como toda proposta neoliberal, considera que tudo é oportunizado aos estudantes em igualdade de condições, já que o Estado oferece, por exemplo, um mesmo currículo e material aos estudantes. As diferenças que surgem são entendidas como de responsabilidade dos professores que trabalharam com o referido material ou ainda dos estudantes que não se esforçaram o suficiente para aprender. Nessa empreitada, as equipes gestoras (direção e coordenação) são colocadas à frente, como responsáveis pelo "controle" do processo de execução do currículo.

Em relação aos grupos que compõem as unidades escolares, a Secretaria da Educação do Estado de São Paulo aponta "a responsabilidade da equipe gestora como formadora de professores e a responsabilidade dos docentes entre si e com o grupo na problemática e na significação dos conhecimentos e das práticas". Ainda se infere a importância dos "[...] gestores, que devem capacitar os professores em seu dia a dia, a fim de que todos se apropriem dessa mudança de foco" (SÃO PAULO, 2010, p. 14).

Essa é a perspectiva de um modelo gerencial, que submete as instituições educacionais, na figura de gestores, professores e estudantes, ao processo de busca por metas, supostamente tidas como necessárias para se alcançar a pretendida qualidade educacional. Todo esse cenário coaduna com a política de valorização docente, presente na lógica do capital, via política de bonificação.

Via de regra, a política de bonificação de professores e de escolas está vinculada ao desempenho dos estudantes em verificações de larga escala, que cobram resultados pré-determinados. Estes, por sua vez, estão vinculados àquelas demandas do mercado de trabalho e da produtividade. Tal política estabelece uma sinergia entre a tríade qualidade, desempenho e mercado, e acaba por impor, aos docentes, um tipo de currículo que atende ao projeto hegemônico conservador. (PEREIRA; SILVA, 2018, p. 538). 
Assim, o que não se avalia é o ponto de partida quando se fala de igualdade. "O que passa a ser discutido é se a escola teve equidade ou não, se conseguiu ou não corrigir as distorções de origem, e esta discussão tira o foco da questão da desigualdade social, base da construção da desigualdade de resultados" (FREITAS, 2012, p. 383).

O Programa São Paulo Faz Escola, na perspectiva governamental, propõe uma educação à altura dos desafios impostos pelo mundo atual. Para o documento, "A sociedade do século XXI é cada vez mais caracterizada pelo uso intensivo do conhecimento, seja para trabalhar, conviver ou exercer a cidadania, seja para cuidar do ambiente em que se vive" (SÃO PAULO, 2010, p. 08), sendo que a educação deve atender aos desafios desse tempo.

Concorda-se que, diante da globalização, o desenvolvimento da tecnologia e a hipercomunicação trouxeram novas necessidades de formação pessoal. Entretanto, ao analisar os ideais que compõem esse material, apoia-se em Sanfelice (2010) e Catanzaro (2012), para quem o Programa São Paulo Faz Escola atende a preceitos neoliberais, expressos, inclusive, nos posicionamentos de seus mentores.

No que tange ao universo educacional, os defensores da concepção neoliberal apregoam que o setor público deve transferir para o setor privado a responsabilidade da educação, com a expectativa de aquecer o mercado e melhorar a educação (GIRON, 2008). Para Freitas (2012), a educação é mais um serviço oferecido pelo mercado, e a qualidade da educação na lógica neoliberal é tida a partir da concorrência entre as escolas que ganham notoriedade diante do desempenho dos estudantes em avaliações externas. As avaliações externas servem como parâmetros para sistematizar e estabelecer os currículos e determinar as estratégias de formação dos professores (CHIZZOTTI; PONCE, 2012).

Para entender a reforma educacional deflagrada no ano de 2008, no Estado de São Paulo, e que favoreceu a criação do Programa São Paulo Faz Escola, faz-se necessário compreender também o ideário político dos membros gestores da época que estavam à frente da esfera executiva e da Secretaria Estadual de Educação.

As reformas neoliberais no Estado de São Paulo começaram em consonância com as reformas em âmbito federal sancionadas pelo ex-presidente Fernando Henrique Cardoso (SANFELICE, 2010; CATANZARO, 2012; RUSSO; CARVALHO, 2012). Seguindo a linha Federal, o governo do Estado de São Paulo buscou novas regulamentações para a educação, sendo que, a partir "[...] do modelo neoliberal 
de Estado, puderam contar com o apoio e incentivo das agências multilaterais de financiamento e formulação de políticas públicas que fomentavam reformas naquela direção (BIRD, BID, PNUD, UNESCO, UNICEF)" (RUSSO; CARVALHO, 2012, p. 277).

Rossi (2011) salienta que a então coordenadora do Programa São Paulo Faz Escola (2007-2010), Maria Inês Finni, fazia parte de uma equipe de profissionais da educação ligada à empresa PRS que prestava serviços de consultoria estudantil ao Banco Mundial e que tem como princípios a centralização das ações, no caso educacional, dos currículos, a fim de se obter um maior controle da operacionalização e objetivos para a atividade de estudo. Os argumentos em defesa desses princípios se deram em decorrência do baixo rendimento da educação nas avaliações externas, tanto na esfera estadual como na esfera federal (CATANZARO, 2012).

Complementando tais ideias, Sanfelice (2010) aponta que o modelo neoliberal de administração pode ser entendido como uma ação política e ideológica que acompanhou o capitalismo por meio de suas transformações históricas, ao fomentar receituários econômicos e sociais. Aos olhos da Secretaria da Educação, esta reforma e a criação de um currículo comum visam melhorar o trabalho docente.

Ao analisar os documentos, em especial o Currículo do Estado de São Paulo da área de Códigos, Linguagens e Suas Tecnologias (SÃO PAULO, 2010), percebe-se um discurso de que o Programa São Paulo Faz Escola busca apoiar o trabalho nas escolas, contribuir com a qualidade da educação paulista e, consequentemente, com a melhoria das aprendizagens dos estudantes. Como exemplo, pode-se mencionar:

O Currículo se completa com um conjunto de documentos dirigidos especialmente aos professores e aos alunos: os Cadernos do Professor e do Aluno, organizados por disciplina/série(ano)/bimestre. Neles, são apresentadas Situações de Aprendizagem para orientar o trabalho do professor no ensino dos conteúdos disciplinares específicos e a aprendizagem dos alunos. Esses conteúdos, habilidades e competências são organizados por série/ano e acompanhados de orientações para a gestão da aprendizagem em sala de aula e para a avaliação e a recuperação. (SÃO PAULO, 2010, p. 08).

Este é o discurso governamental, materializado no referido currículo (SÃO PAULO, 2010). Contraditoriamente, o que se percebe é que a implantação atende às exigências presentes nas avaliações externas (SANFELICE, 2010). Pereira (2018, p. 111) complementa que esse é o modelo difundido pela OCDE, ou seja, 
totalmente alinhado às características da escola-empresa, ao passo que se exige por meio das avaliações externas que os estudantes estejam aptos e adaptados às demandas do mercado (competências e habilidades).

De acordo com Sanfelice (2010), o São Paulo Faz Escola pratica um gerenciamento curricular a ser trabalhado em sala de aula, em todas as disciplinas e em todas as unidades escolares públicas do Estado de São Paulo. A implantação de um currículo comum para todo o Estado fere a autonomia do professor, constitucionalmente estabelecida, forçando-o a reproduzir aquilo que a Secretaria da Educação construiu.

Quando o Estado assume a padronização curricular, no plano das aparências, cria-se a ilusão de que se está garantindo a igualdade de oportunidades para estudantes que residem em diferentes contextos. Todavia, no âmbito da essência, dialeticamente, identifica-se que os professores acabam se tornando reféns de um processo no qual eles se tornam meros reprodutores de um currículo que não considera as especificidades histórico-culturais.

Pelo contrário, é um currículo organizado e ideologicamente amarrado aos interesses do capital. Considerando-se que a eficiência da ideologia dominante está na capacidade de silenciar a realidade, ao ocultar os fatos e mascará-los, infere-se que os métodos pedagógicos alinhados aos preceitos neoliberais contribuem para a manutenção de relações sociais desiguais (MEYER; RAMÍREZ, 2002).

\subsection{O currículo oficial a partir do discurso de competências e habilidades}

Após o seu início, o Programa São Paulo Faz Escola produziu e enviou a todas as unidades escolares do Estado uma espécie de apostilado bimestral, composto de um caderno de exercício para os estudantes e um caderno para o professor em cada uma das diferentes disciplinas. Dividido em quatro situações de aprendizagem, o material estipulava o número de aulas necessárias para se trabalharem as competências e habilidades, os conteúdos, os procedimentos metodológicos e a avaliação (CATANZARO, 2012; FERNANDES, 2014). Nessa perspectiva, o Currículo do Estado de São Paulo menciona:

Esses conteúdos, habilidades e competências são organizados por série/ ano e acompanhados de orientações para a gestão da aprendizagem em sala de aula e para a avaliação e a recuperação. Oferecem também sugestões de métodos e estratégias de trabalho para as aulas, experimentações, 
projetos coletivos, atividades extraclasse e estudos interdisciplinares. (SÃO PAULO, 2010, p. 8).

A partir de Silva e Felicetti (2014), infere-se que a noção de competências e habilidades assumida no São Paulo Faz Escola começou a ser utilizada em nosso país a partir da década de 1990. No Brasil, existem vários documentos que salientam a aprendizagem por competências e habilidades, tais como os Parâmetros Curriculares Nacionais (BRASIL, 2000), o Sistema de Avaliação da Educação Básica (SAEB) e a Provinha Brasil.

No São Paulo Faz Escola, há a defesa de que a educação deve "promover os conhecimentos próprios de cada disciplina articulando às competências e habilidades. É com essas competências e habilidades que os estudantes contarão para fazer a leitura crítica do mundo" (SÃO PAULO, 2010, p. 12). No documento produzido pelo Estado de São Paulo, que orienta inclusive a avaliação do SARESP, constata-se que serão analisadas as competências cognitivas dos estudantes. $O$ documento entende como competências cognitivas as "modalidades estruturais da inteligência. Modalidades, pois expressam o que é necessário para compreender ou resolver um problema" (SÃO PAULO, 2009, p. 13).

O documento divide em três grupos as habilidades exigidas na avaliação. O primeiro grupo exige que o estudante possa observar, identificar, reconhecer, apontar, localizar; descrever, discriminar, constatar, representar gráfica e quantitativamente. $\mathrm{O}$ que se pretende observar na avaliação é se o estudante adquiriu as habilidades, a fim de que entenda as informações apresentadas antes de decidir pela resposta (SÃO PAULO, 2009).

O segundo grupo exige que o estudante saiba classificar, seriar, ordenar, conservar, compor e decompor, fazer antecipações, calcular por estimativa, medir e interpretar. O que se exige é que ele possa traduzir em ações o conteúdo e o contexto apresentado. Por fim, o terceiro grupo exige as habilidades de analisar, aplicar relações ou conhecimentos, fatos e princípios, avaliar, criticar, analisar e julgar, explicitar causas e efeitos, apresentar conclusões, levantar suposições, fazer prognósticos, fazer generalizações indutivas e construtivas e justificar, o que exige do estudante planejamento e estabelecimento de estratégias para resolver problemas prováveis e/ou possíveis (SÃO PAULO, 2009).

Conforme Zabala e Arnau (2010), o termo "competência” não surgiu no campo educacional, ele é decorrente da esfera do mundo do trabalho. "Portanto, a com- 
petência consistirá na intervenção eficaz nos diferentes âmbitos da vida, mediante ações nas quais se mobilizam, ao mesmo tempo e de maneira inter-relacionada, componentes atitudinais, procedimentos e conceituais" (ZABALA; ARNAU, 2010, p. 11).

Assim entendido, competências são situações que instigam o estudante a tomar decisões para resolver problemas que, depois serão transpostos para a vida exterior à escola. Para Perrenoud (2000), um dos defensores dessa perspectiva, um currículo pensado por competências possibilitará ao estudante a aquisição de conhecimentos para enfrentar situações diversas em seu mundo e no mundo do trabalho. O pensamento de Perrenoud aparece de forma implícita no Currículo do Estado de São Paulo (2010).

A base curricular para todas as disciplinas está pautada na Pedagogia das Competências, prevendo para cada situação de aprendizagem competências e habilidades a serem desenvolvidas pelos estudantes que frequentam as escolas da Rede Estadual.

Freitas (2012), apesar de não abordar em específico a educação por competências e habilidades, mas sim a política neoliberal tecnicista, enfatiza que existe um estreitamento do currículo em prol das avaliações externas. A escola passa a se preocupar com a parte cognitiva dos estudantes, e não mais com a formação integral desses, ao deixar de lado a criatividade, as artes, a afetividade, o desenvolvimento corporal e a cultura.

Para Arce (2001), quando a educação privilegia os livros didáticos ou manuais em seus currículos, como é o caso do estado de São Paulo, não se exige do professor um conhecimento aprofundado e tampouco uma formação sólida, preconiza-se apenas o domínio de algumas habilidades técnicas e saber manusear os livros e os manuais. Diante desse cenário, Bruno (2011, p. 554) problematiza:

Como se pode ver, ainda que a produção de capacidade de trabalho esteja exigindo mais anos de escolaridade e conhecimentos mais complexos, essa produção está longe de incluir o domínio de um pensamento teórico sólido e investigativo, ao contrário, trata-se apenas de garantir o aprendizado de conhecimento meramente instrumental e as competências trabalhadas são de caráter adaptativo às exigências do sistema.

O currículo paulista confere ênfase para que, após o término do Ensino Médio, os estudantes da escola pública possam buscar cursos nas áreas de educação técnica e profissionalizante (SÃO PAULO, 2010). Se os estudantes das escolas 
públicas, ao terminarem a educação básica, deverão buscar "cursos técnicos", como propõe a Secretaria, fica evidente uma segregação na educação quanto ao prosseguimento dos estudos e nos futuros postos de trabalho.

A própria Secretaria afirma que, para o estudante, "as competências para trabalhar em ilhas de produção, associar concepção e execução, resolver problemas e tomar decisões tornam-se mais importantes do que conhecimentos e habilidades voltados para postos específicos de trabalho" (SÃO PAULO, 2010, p. 23).

Os estudantes da classe média alta que estudam em escolas particulares dos grandes sistemas de ensino são preparados para prestarem os vestibulares das universidades públicas e ocuparem as vagas dos cursos de graduação mais valorizados social e financeiramente. Por sua vez, os estudantes da rede pública são preparados para os cursos técnicos ou, quando conseguem o ingresso no Ensino Superior, estudam em faculdades particulares, em cursos geralmente voltados ao campo educacional, no período noturno.

Na visão de Rossi (2011), quando os documentos oficiais expõem que preparam os jovens para o mundo do trabalho, estão apenas direcionando quem serão os futuros jovens operários das máquinas das grandes empresas e corporações. A proposta é de que os estudantes se tornem flexíveis na execução de funções, pois, ao entrarem no mercado de trabalho, assim como no toyotismo, no polifuncionalismo, possam exercer diversas funções nas esferas da produção.

Para Galuch e Sforni (2011) e Saviani (2010), o ensino praticado à base das competências e habilidades em um primeiro momento pode parecer um avanço na educação, visto que traz uma nova perspectiva na aprendizagem, ao romper com as práticas conteudistas das teorias tradicionais. Entretanto a educação que privilegia as competências e as habilidades enfoca apenas as que são exigidas do mundo globalizado, a serviço do acúmulo de capital pelas grandes empresas internacionais (GALUCH; SFORNI, 2011; FERNANDES, 2014).

Esses são os mesmos ideais, pretendidos pela Secretaria da Educação, acrescidos ao discurso de que devem desenvolver nos jovens o espírito de solidariedade, a fim de que aprendam a viver em comunidade, a respeitar os diferentes, ou seja, uma educação voltada à cidadania (SÃO PAULO, 2010). Todavia questiona-se "Por que essas capacidades e não outras? Não se trata de uma formação contraditória? Como formar sujeitos competitivos e, ao mesmo tempo, solidários?" (GALUCH; SFORNI 2011, p. 56). 
O que se espera no fundo é que a escola forme pessoas para a lógica do processo de produção, além de preparar os jovens para trabalharem em diversas ilhas comerciais e a desempenharem diversos papéis nas indústrias. A escola também objetiva prepará-los a se relacionar com as pessoas, bem como que aprendam a obedecer às determinações dos seus superiores (GALUCH; SFORNI, 2011).

Mazzeu (2007) afirma que a educação por competências e habilidades contrapõe-se à perspectiva histórico-crítica de educação, que tem como premissa o desenvolvimento humano integral. Como a pedagogia das competências está a serviço do capital, os estudantes não são vistos como indivíduos, e sim como "números" que devem corresponder às expectativas de quem pensou e produziu o currículo.

Tal visão de currículo é oposta à defendida pelos autores deste artigo, visto que se entende que a escola pública deve conduzir o estudante à apropriação do conhecimento em suas diferentes dimensões (científico, filosófico e artístico), a fim de que os estudantes possam ampliar suas concepções sobre o mundo e si mesmos. Todavia há de se registrar que nenhum conhecimento produzido no atual modelo de organização social está isento da alienação e de ideologias. Trabalhar com educação escolar está associado ao trabalho com lutas ideológicas (DUARTE, 2015). Daí a importância de um ensino pautado pelo mercado de trabalho, e não para o mercado de trabalho (CHIZZOTTI; PONCE, 2012).

\section{CONSIDERAÇÕES FINAIS}

Esta pesquisa buscou compreender o discurso oficial do então denominado Currículo do Estado de São Paulo. O que se pôde notar é que o Currículo é uma extensão da política educacional implantada no Brasil na década de 1990, pela mesma equipe que fomentou o currículo estadual. Os dois são políticas curriculares neoliberais e visam uma educação para atender às necessidades de mercado, ao preparar as pessoas para que possam exercer diferentes funções na sociedade.

O Programa São Paulo Faz Escola, implantado no Estado de São Paulo desde 2009, vem atender a determinações das políticas neoliberais de educação. Os órgãos como FMI, BM, OCDE, BIRD, BID, UNESCO e UNICEF, ao proporem incentivos e financiamentos ao Brasil e outros países, exigem reformas no campo educacional que visam preparar os jovens para a adaptação ao mercado de trabalho. 
Em relação ao mundo do trabalho, a escola pública estaria preparando a maioria dos jovens para um mercado de trabalho precário, visto que, para a Secretaria da Educação, o estudante da escola pública, ao término do Ensino Médio, estaria preparado para ingressar em cursos técnicos e profissionalizantes.

Constatou-se, ainda, que o currículo é pragmático, sendo oferecida uma versão pronta e acabada para professores e estudantes, além de que, ao privilegiar as competências e habilidades, os conteúdos em termos de densidade conceitual acabam sendo secundarizados.

\section{REFERÊNCIAS}

ADRIÃO, Theresa; DAMASO, Alexandra; GALZERANO, Luciana Sardenha. A adoção de Sistemas Privados de Ensino em escolas públicas de educação infantil: reflexões a partir do perfil dos professores. Revista e-Curriculum, São Paulo, n. 11, v. 2, p. 43460, ago. 2013. Disponível em: http://revistas.pucsp.br/index.php/curriculum/article/ viewFile/16616/12479. Acesso em: 28 dez. 2018.

ANDERSON, Perry. Balanço do neoliberalismo. In: SADER, Emir; GENTILI, Pablo (Org.). Pós-neoliberalismo: as políticas sociais e o estado democrático. Rio de Janeiro: Paz e Terra, 1995. p. 9-23.

ARCE, Alessandra. Compre o kit neoliberal para a educação e ganhe grátis os dez passos para se tornar um professor reflexivo. Educação \& Sociedade, Campinas, SP, ano XXII, n. 74, p. 251-83, abr. 2001.

BRASIL. Ministério de Educação e Cultura. LDB - Lei n. 9394/96, de 20 de dezembro de 1996. Estabelece as diretrizes e bases da Educação Nacional. Brasília: MEC, 1996.

BRASIL. Parâmetros Curriculares Nacionais (PCNs). Ensino Médio. Brasília: MEC/SEF, 2000.

BRUNO. Lúcia. Educação e desenvolvimento econômico no Brasil. Revista Brasileira de Educação, Rio de Janeiro, v. 16, n. 48, p. 545-62, set./dez. 2011. Disponível em: http:// www.scielo.br/scielo.php?script=sci_arttext\&pid=S1413-24782011000300002\&lng=en \&nrm=iso. Acesso em: 15 out. 2019

CATANZARO, Fabiana Olivieri. O programa São Paulo Faz Escola e suas apropriações no cotidiano de uma escola de ensino médio. 2012. 126 f. Dissertação (Mestrado em Educação)- Universidade de São Paulo, São Paulo, 2012.

CHIZZOTTI, Antônio; PONCE, Branca Jurema. O currículo e os sistemas de ensino no Brasil. 
Currículo sem Fronteiras, v. 12, n. 3, p. 25-36. set./dez., 2012. Disponível em: http://www. curriculosemfronteiras.org/vol12iss3articles/chizzotti-ponce.pdf Acesso em: 10 out. 2019.

DUARTE, Newton. A importância da concepção de mundo para a educação escolar: porque a Pedagogia Histórico-Crítica não endossa o silêncio de Wittgenstein. Germinal: Marxismo e Educação em Debate, Salvador, v. 7, n. 1, p. 8-25, jun. 2015. Disponível em: https:// portalseer.ufba.br/index.php/revistagerminal/article/view/12808 Acesso em: 10 fev. 2016.

FERNANDES, Sandra Faria. Reforma curricular na escola: análise do processo de implantação da Proposta Curricular no estado de São Paulo - um novo olhar. 2014. 301f. Tese (Doutorado em Educação)- Pontifícia Universidade Católica de São Paulo, São Paulo, 2014.

FREITAS, Luiz Carlos. Os reformadores empresariais da educação: da desmoralização do magistério à destruição do sistema público de educação. Educação \& Sociedade, Campinas, SP, v. 33, n. 119, p. 379-404, abr./jun. 2012 Disponível em: http://www.scielo.br/scielo. php?pid=S0101-73302012000200004\&script=sci_abstract\&tlng=pt. Acesso em: 20 mar. 2019.

GALUCH, Maria Terezinha Bellanda; SFORNI, Marta Sueli de Faria. Interfaces entre políticas educacionais prática pedagógica e formação humana. Práxis Educativa, Ponta Grossa, PR, v. 6, n. 1, p. 55-66, jan./jun. 2011. Disponível em: https://www.revistas2.uepg.br/index. php/praxiseducativa/article/view/1862 Acesso em: 20 mar. 2019.

GIAVARA, Ana Paula. Entre o discurso e a prática: a implementação do currículo de história para o ensino médio no programa educacional "São Paulo Faz Escola". 2012. 206f. Dissertação (Mestrado em Educação) - Universidade Estadual Paulista, Marília, SP, 2012.

GIRON, Graziela Rossetto. Políticas públicas, educação e neoliberalismo: o que isso tem a ver com cidadania? Revista de Educação da PUC-Campinas, Campinas, SP, n. 24, p. 1726, jun. 2008. Disponível em: http://periodicos.puc-campinas.edu.br/seer/index.php/ reveducacao/article/view/109 Acesso em: 17 mar. 2019.

HADDAD, Sérgio. Introdução. In: HADDAD, Sérgio. Banco Mundial, OMC e FMI: o impacto nas políticas educacionais. São Paulo, Cortez, 2008. p. 7-14.

LEANDRO FILHO, José Antônio. Análise da concepção política do currículo São Paulo Faz Escola e o papel da disciplina de Filosofia. 2015. 82f. Dissertação (Mestrado em Educação) - Universidade do Oeste Paulista, Presidente Prudente, SP, 2015.

LOPES, Alice Casimiro; MATHEUS, Danielle dos Santos. Sentidos de qualidade na política de currículo (2003-2012). Educação e Realidade, Porto Alegre, v. 39, n. 2, p. 337-57, abr./ jun. 2014. Disponível em: https://seer.ufrgs.br/educacaoerealidade/article/view/41018. Acesso em: 23 mar. 2019. 
LUDKE, Menga; ANDRÉ, Marli Eliza Dalmaso Afonso. Pesquisa em educação: abordagens qualitativas. São Paulo: EPU, 1986.

MALTA, Shirley Cristina Lacerda. Uma abordagem sobre currículo e teorias afins visando à compreensão e mudança. Espaço do Currículo, João Pessoa, PB, v. 6, n. 2, p. 340-54, maio/ago. 2013. Disponível em: https://periodicos.ufpb.br/ojs2/index.php/rec/article/ view/3732 Acesso em: 23 mar. 2019.

MAZZEU, Lidiane Teixeira Brasil. A pedagogia histórico-crítica como expressão teórica do marxismo na educação e a crítica à formação por competências. Revista de Educação da PUC Campinas, Campinas, SP, n. 23, p 43-53, nov. 2007. Disponível em: http://periodicos.puccampinas.edu.br/seer/index.php/reveducacao/article/view/168 Acesso em: 17 mar. 2019.

MEYER, John; RAMÍREZ, Francisco. La institucionalización mundial de la educación. In: SCHRIEWER, J. Formación del discurso en la educación comparada. Barcelona: Ediciones Pomares, 2002. p. 91-111.

PAES, Milena Veneziano; RAMOS, Géssica Priscila. O Programa "São Paulo Faz Escola" e seu modelo de gestão tutelada. Comunicações, Piracicaba, SP, v. 21, n. 2, p. 53-66, jul./ dez. 2014. Disponível em: https://www.metodista.br/revistas/revistas-unimep/index. php/comunicacoes/article/view/1817 Acesso em: 17 mar. 2019.

PEREIRA, Rodrigo da Silva. Avaliação de sistemas e política de competências e habilidades da OCDE. Práxis Educativa, Ponta Grossa, PR, v. 13, n. 1, p. 107-27, jan./abr. 2018. Disponível em: https://www.revistas2.uepg.br/index.php/praxiseducativa/article/ view/10799 Acesso em: 13 fev. 2019.

PEREIRA, Rodrigo da Silva; SILVA, Maria Abádia da. Estado capitalista brasileiro e organismos internacionais: continuidades e aprofundamentos das reformas educacionais. Revista HISTEDBR on-line, Campinas, SP, v. 18, n. 2 [76], p. 523-44, abr./jun. 2018. Disponível em: https://periodicos.sbu.unicamp.br/ojs/index.php/histedbr/article/view/8651372 Acesso em: 17 mar. 2019.

PERRENOUD, Philippe. 10 novas competências para ensinar. Porto Alegre: Artes Médicas Sul, 2000.

ROSSI, Murilo. A nova proposta curricular do ensino de Geografia na rede estadual de São Paulo: um estudo. 2011. 206f. Dissertação (Mestrado em Educação), Faculdade de Filosofia, Letras e Ciências Humanas, Universidade de São Paulo, São Paulo. 2011.

RUSSO, Miguel; CARVALHO, Celso. Reforma e políticas de educação do governo do estado de São Paulo (2007-2011). Série-Estudos, Campo Grande, MS, n. 34, p. 275-89, jul./dez. 
2012. Disponível em: http://www.serie-estudos.ucdb.br/index.php/serie-estudos/article/ view/106/58. Acesso em: 13 fev. 2019.

SANFELICE, José Luís. A política educacional do Estado de São Paulo: apontamentos. Nuances: Estudos Sobre Educação, Presidente Prudente, SP, v. 17, n. 18, p. 146-59, jan./dez. 2010. Disponível: http://revista.fct.unesp.br/index.php/Nuances/article/view/730/742 Acesso em: 19 mar. 2019.

SÃO PAULO (Estado). Secretaria da Educação de São Paulo cria nova agenda para educação pública. Diário Oficial, São Paulo, v. 117, n. 157, 21 ago. 2007a. Disponível em: https://www.imprensaoficial.com.br/DO/BuscaDO2001Documento_11_4.aspx?lin k=\%2f2007\%2fexecutivo\%2520secao\%2520i\%2fagosto\%2f21\%2fpagnot_0001_08AJO 1HK656IHe7FH9EVP5LTO4T.pdf\&pagina=I\&data=21/08/2007\&caderno=Executivo\%20 I\&paginaordenacao=1. Acesso em: 2 jan. 2019.

SÃO PAULO (Estado). Secretaria da Educação. Resolução SE n. 92, de 19 de dezembro de 2007. Estabelece diretrizes para a organização curricular do ensino fundamental e médio nas escolas estaduais. São Paulo: SEE, 2007b. Disponível em: http://siau.edunet.sp.gov. br/ItemLise/arquivos/92_07.htm. Acesso em: 18 dez. 2018.

SÃO PAULO (Estado). Lei Complementar n. 1.078, de 17 de dezembro de 2008. Institui Bonificação por Resultados - BR, no âmbito da Secretaria da Educação, e dá providências correlatas. Diário Oficial, São Paulo, v. 118, n. 239, 18 dez. 2008. Disponível em: https:// www.imprensaoficial.com.br/DO/BuscaDO2001Documento_11_4.aspx?link=\%2f20 08\%2fexecutivo\%2520secao\%2520i\%2fdezembro\%2f18\%2fpag_0001_44LHV39TU CQS9e8JVKRQUHNQ7SL.pdf\&pagina $=1 \&$ data $=18 / 12 / 2008 \&$ caderno=Executivo $\% 20$ I\&paginaordenacao=100001. Acesso em: 3 jan. 2019.

SÃO PAULO (Estado). Matriz de referência para avaliação do Saresp. Secretaria de Educação. São Paulo: SEE, 2009.

SÃO PAULO (Estado). Currículo do Estado de São Paulo: ciências humanas e suas tecnologias - ensino fundamental - ciclo II e ensino médio. 1. ed. rev. Secretaria de Educação. São Paulo: SEE, 2010.

SÃO PAULO (Estado). Ciências humanas e suas tecnologias. Caderno do professor, Primeiro, Segundo e Terceiro anos, Vol. 1 e 2. Ensino Médio/Secretaria de Educação. São Paulo: SEE, 2014a.

SÃO PAULO (Estado). Ciências humanas e suas tecnologias. Caderno do aluno primeiro, Segundo e Terceiro anos, Vol. 1 e 2. Ensino Médio/Secretaria de Educação. São Paulo: SEE, 2014b. 
SAVIANI, Dermeval. Ciência e educação na sociedade contemporânea: desafios a partir da Pedagogia Histórico-Crítica. Revista Faz Ciência, Francisco Beltrão, PR, v. 12, n. 16, p. 13-36, jul./dez. 2010. Disponível em: http://e-revista.unioeste.br/index.php/fazciencia/ article/viewFile/7434/5778 Acesso em: 20 fev. 2019.

SEVERINO, Antônio Joaquim. Metodologia do trabalho científico. São Paulo: Cortez, 2012.

SILVA, Gabriele Bonoto; FELICETTI, Vera Lucia. Habilidades e competências na prática docente: perspectivas a partir de situações-problema. Educação Por Escrito, Porto Alegre, v. 5, n. 1, p. 17-29, jan./jun. 2014. Disponível em: http://revistaseletronicas.pucrs.br/ojs/ index.php/porescrito/article/view/14919 Acesso em: 13 fev. 2019.

ZABALA, Antoni; ARNAU, Laia. Como aprender e ensinar competências. Porto Alegre: Artmed, 2010.

\section{Sobre os autores:}

José Antônio Leandro Filho: Mestre em Educação pela Universidade do Oeste Paulista (Unoeste). Vice-diretor de unidade escolar da Secretaria Estadual de Educação de São Paulo (SEESP). E-mail: z2antonio@hotmail.com, Orcid: http://orcid.org/0000-0001-6934-5363

Marcos Vinicius Francisco: Doutor em Educação pela Universidade Estadual Paulista (UNESP), campus de Presidente Prudente, SP. Docente do Curso de Educação Física da Universidade Estadual de Maringá, Campus Regional do Vale do Ivaí (UEM/CRV) e do Programa de Pós-Graduação em Educação (PPE/UEM); Coordenador e docente permanente do Programa de Pós-Graduação em Educação da Universidade do Oeste Paulista (UNOESTE). E-mail: marcos_educa01@yahoo.com.br, Orcid: http://orcid.org/0000-0002-5410-2374

Erika Porceli Alaniz: Doutora em Educação pela Universidade de São Paulo (USP). Docente do Programa de Pós-Graduação Stricto Sensu - Mestrado Profissional em Educação da Universidade Estadual de Mato Grosso do Sul (UEMS), Campo Grande. E-mail: a.porcelierika@gmail.com, Orcid: http://orcid.org/0000-0002-8855-4045

\section{Recebido em 16 de janeiro de 2019. Aprovado em 5 de novembro de 2019.}

